\title{
Estimation of stature from percutaneous length of tibia in the population of Birgunj, Nepal
}

Sah RP', Shrestha I $^{2}$

${ }^{1}$ Rajendra Prasad Sah, Professor of Anatomy, MB Kedia Dental College, Birgunj, Nepal; ${ }^{2}$ lju Shrestha, Resident, Department of Anatomy, Kathmandu Medical College Teaching Hospital, Kathmandu, Nepal.

\section{Abstract}

Background: Stature estimation is one of the important parameters in establishment of the identity of a person. As said "Identification is an individual's birth right", stature of an individual is an inherent character. Mass disasters like air crash, terrorist attacks etc. are quite frequent these days because of which dismembered body parts are being frequently brought to the medico-legal experts for generating data for identification.

Objective: The objective of this study is to estimate the stature from percutaneous tibia length (PCTL).

Methods: This prospective study consisted of 150 males and 150 females between the age group of 20 to 30 years, born and brought up in Nepal. The duration of study is one year from October 2012 to October 2013. The parameters measured were stature and percutaneous tibia length. To find out the correlation of percutaneous tibial length with that of the height and to evolve a regression equation formula necessary statistical evaluation has been done on the data obtained from 300 adult participants comprising of 150 males and 150 females. By using the regression equation formula so derived the height of an individual can be calculated by the help of percutaneous tibial length. The data were analysed using Statistical Package for Social Sciences (SPSS) version 11. P value less than 0.05 was considered as a significant.

Results: It was found that a significant positive correlation existed between the stature and percutaneous tibial length with a correlation coefficient $(r)$ of 0.562 in males and 0.71 in females and $p$ value $<0.001$. Stature was estimated from PCTL using simple regression analysis Stature $(\mathrm{cm})=88.898+2.027 * \mathrm{PCTL}(\mathrm{cm})$ for males and Stature $(\mathrm{cm})=75.954+2.253^{*}$ PCTL $(\mathrm{cm})$ for females.

Conclusion: A highly significant correlation of stature was observed with percutaneous length in both sexes. The result of this study would be useful for anthropologists and forensic medicine experts. Stature can be estimated from PCTL using simple regression analysis.

Key words: Anthropology, Forensic, percutaneous tibia length (PCTL).

\section{INTRODUCTION}

P ersonal identification means determination of individuality of a person. It may be complete (absolute) or incomplete (partial). Complete identification means absolute fixation of individuality of a person. Partial identification implies ascertainment of only some facts about the identity of the person. Age, sex and stature are the primary characteristics of identification'. Stature is one of the various parameters of identification of the individuality of a person. It is well known that there is a relationship between the height of the person and various parts of the body like head, trunk

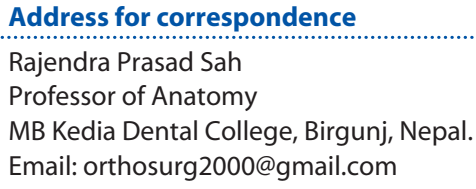

and lengths of the upper and lower limbs. Assessing the height of an individual from measurements of different parts has always been of immense interest to the anatomists, anthropologists and forensic medicine experts. Kaore measured heights of the participants in standing position and percutaneous tibial length and found positive correlation between them ${ }^{2}$. Studies have been conducted in different regions on different races, hence their data and statistical formulae cannot be generalized. Estimation of stature of an individual from the skeletal materials or from the mutilated or amputated limbs or parts of the limbs has obvious significance in the personal with the forensic identification. Many studies have been conducted in different ethnic groups to estimate stature from the length of long limb bones, because the long limb bones have got a definite correlation to the height of an individual ${ }^{1,3-9}$. A few studies have proved that the percutaneous measurements of 
long limb bones are useful in the estimation of living stature $^{10-12}$. However, stature varies with the race and is determined by genetics of a person, geographical location, environment and climatic conditions. Since no studies have been documented in the Nepalese population, an attempt has been made to estimate stature of an individual from percutaneous lengths of the tibia in Nepalese adult population.

\section{METHODS}

The study included 150 males and 150 females of age 20-30 years, selected purposively from Birgunj area of Nepal. The duration of study was one year from October 2012 to October 2013. The participants included were with absence of physical injuries, bone pathologies, bone surgery, visible shortening of the limbs or any other pathological process in medical history that might have influenced the length of long bones. The participants with any congenital deformities, trauma and pathological conditions affecting the height were also excluded. Informed verbal consent was taken from the participants before taking the measurements. The ethical clearance was taken from institutional ethical review committee of MB Kedia Dental College.

Stature: Height of the participant was measured in standing position using stadiometer. The participants were asked to stand barefoot on the board of a standard stadiometer with both feet in close contact with each other, trunk braced along the vertical board, and the head adjusted in Frankfurt's plane ${ }^{11}$. The measurement was taken in centimetres, by bringing the horizontal sliding bar to the vertex.

Percutaneous tibial length: The participant was made to sit with thigh in a straight line, knee flexed at $90^{\circ}$ and the foot rotated laterally, that would make the bony projections prominent. Then, length of the right tibia was measured as the distance between the superiormost margin of the medial condyle to the inferior-most margin of the medial malleolus.

Statistical analysis: The data were analysed using Statistical Package for Social Sciences (SPSS) version 11. The data were analyzed for range, mean, standard deviation and standard error. The linear and multiple regression equations were derived for estimating stature from percutaneous length of tibia of individual for assessing the correlation between the stature and the length of the bones, the Pearson's correlation coefficient was calculated and its significance was tested by Students-t test. $P$ value less than 0.05 was considered as significant.

\section{RESULTS}

PCTL considered under various parameters in males and females showed that stature and PCTL are more in males than in females. The present study revealed that standing height of many individuals were same, but their PCTL differed, i.e. the contribution of tibial length to the stature of a person varied from person to person, even for a given height. Keeping this in view, mean of stature and PCTL were taken into consideration. Stature of the study population ranged from 140 to $180 \mathrm{~cm}$ in males and 145 to $166.2 \mathrm{~cm}$ in females with mean value 165.03 $\mathrm{cm}$ and $154.59 \mathrm{~cm}$ respectively. Descriptive statistics of the study sample are shown in Table 1. Percutaneous length of tibia was longer in males compared to females. The linear regression equations for the estimation of stature from the lengths of tibia are shown in Table 2. Correlation coefficients $(r)$ of height and PCTL were calculated for males and females. The value of ' $r$ ' for males was 0.562 and for females 0.71 . Both these values were statistically significant (Table 2).

Table 1: Different parameters of stature and PCTL in males and females

\begin{tabular}{lcccc}
\hline \multirow{2}{*}{ Parameters } & \multicolumn{2}{c}{ Stature $(\mathbf{c m})$} & \multicolumn{2}{c}{ PCTL $(\mathbf{c m})$} \\
\cline { 2 - 6 } Range & Male & Female & Male & Female \\
Mean & $140-180$ & $145-166.2$ & $32-42$ & $31-39$ \\
Standard Deviation & 165.03 & 154.59 & 37.57 & 2.16 \\
p value & 7.81 & 5.61 & & $<0.005$ \\
\hline
\end{tabular}

Student $t$ test is used to calculate $p$ value. 


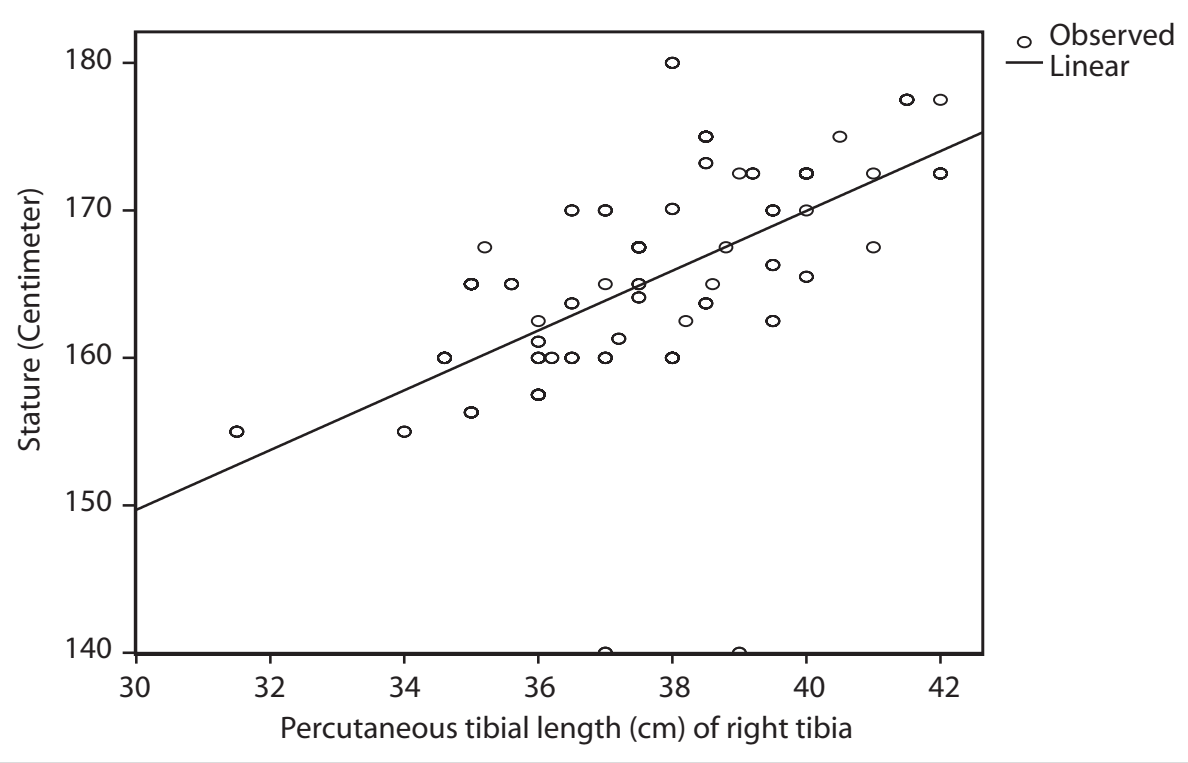

Figure 1:Scatter diagram showing correlation of stature and PCTL, along with regression line in males.

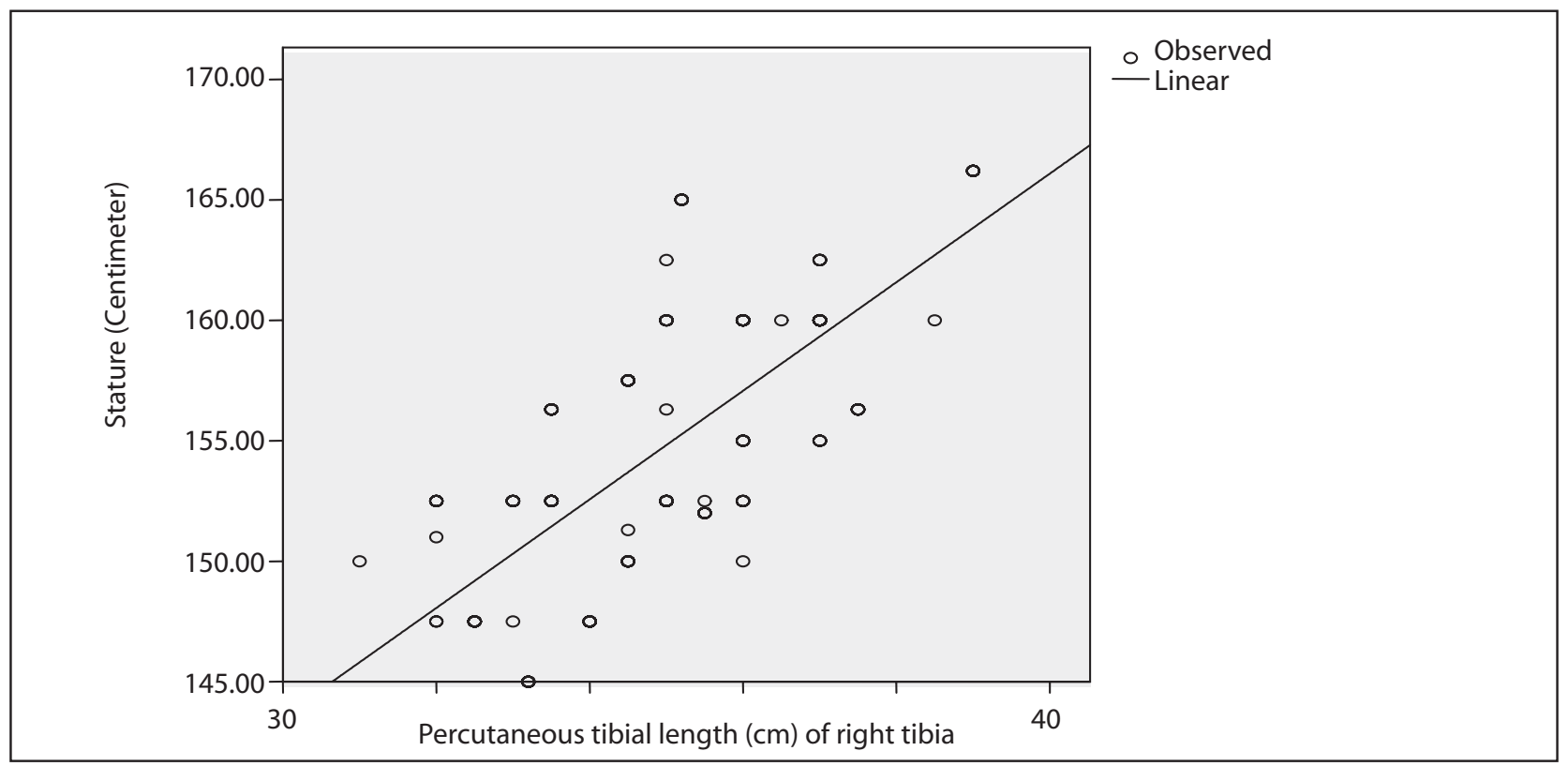

Figure 2: Scatter diagram showing correlation of stature and PCTL, along with regression line in females.

\section{Table 2: Regression Analysis between Stature and PCTL in males and females}

\begin{tabular}{lcc}
\hline \multicolumn{1}{c}{ Parameter } & Male & Female \\
\hline Linear regression equation & $\mathrm{Y}=88.898+2.027 \mathrm{X}^{*}$ & $\mathrm{Y}=75.954+2.253 \mathrm{X}^{*}$ \\
\hline Standard error & 6.479 & 3.99 \\
\hline Correlation coefficient $(r)$ & 0.562 & 0.71 \\
\hline $95 \%$ confidence interval of $(r)$ & 0.444 to 0.705 & 0.629 to 0.769 \\
\hline Coefficient of determination $\left(R^{2}\right)$ & 0.315 & 0.495 \\
Intercept & 88.898 & 75.954 \\
Slope & 2.027 & 2.253 \\
\hline p value & $<0.001$ & $<0.001$ \\
\hline
\end{tabular}

${ }^{*} X$ : percutaneous tibial length $(\mathrm{cm}), \mathrm{Y}$ : Stature $(\mathrm{cm})$ 


\section{DISCUSSION}

Estimation of stature from bones plays an important role in identifying unknown bodies, parts of bodies or skeletal remains. In the present study, an attempt has been made to show relationship between stature and percutaneous tibial length in males and females of Nepalese population. The study was conducted on 300 individuals born and brought up in Nepal. As individuals stop growing in height on completion of union of the epiphysis and the diaphysis, which is usually by the age of 18 to 20 years, all individuals considered for the purpose of study were above the age of 20 years, also after 30 years there is regression of the intervertebral disc, so the participants below 30 years are included in the study. The present study revealed that standing height of many individuals was same, but their percutaneous tibial lengths (PCTL) differed, i.e. the contribution of tibial length to the stature of a person varied from person to person, even for a given height. Keeping this in view, mean of stature and PCTL were taken into consideration. Trotter and Gleser had designed the most commonly used equations ${ }^{13}$. The lower limb length is the greatest contributor to standing height; hence most of the predictive equations are based on the length of the long bones of the lower limb, the femur, tibia, and fibula. To address the issue of poor preservation and fragmented and incomplete bones, Steele had developed equations for predicting the complete length of the long bone. Correlation coefficients ( $r$ ) of height and PCTL were calculated for males and females ${ }^{14}$. The value of ' $r$ ' for males was 0.98 and for females 0.95 . Both these values were statistically significant. Since there was high correlation between the height and PCTL, a simple regression analysis was done between them for males and females, to predict height from PCTL ${ }^{15}$. For estimation of height from PCTL, a simple regression formula was derived as follows: For male: Stature in $\mathrm{cm}(\mathrm{Y})=88.898+2.027 \mathrm{X}$; for females: Stature in $\mathrm{cm}(\mathrm{Y})=75.954+2.253 \mathrm{X}$ where, $\mathrm{Y}=$ stature and $X=$ percutaneous tibial length. Mohanty et al ${ }^{9}$ found a correlation coefficient ( 0.562 in males and 0.710 in females), similarly Ozaslan et $\mathrm{al}^{16}$ derived correlation coefficient ( 0.740 in males and 0.790 in females). The highest correlations were observed between stature and tibial length, which explains that the weight bearing bones are better indicators of the stature. The estimated height so derived is acceptable within a range of error and was in close approximation with that of the observed height. Celbis ${ }^{14}$ derived regression formulae and found a good correlation. Bhavna and Surender Nath ${ }^{15}$ in their study on male Shia Muslims in Delhi derived the linear regression equation which is comparable to our study. In our study we broadened the spectrum of assessment by including both males and females which has not been done in the above studies. KR Nagesh ${ }^{17}$ estimated the stature from length of tibia, radius and ulna in medical students belonging to South Indian population. In his study, the multiple regression equations parameters showed higher correlation coefficients (0.829 in males and 0.747 in females). The regression equations were derived which are helpful in estimating stature from the lengths of tibia, radius and ulna in South Indian population. The regression equations derived from this study do not match with any of the other races, nations or the religions studied, as these are individually different since there are various ethnic group people living in different geographical places with different nutritional habit and different genetic characters. Thus the effect of ethnicity in the height and length could be certainly different. So these finding substantiates the views expressed by other workers that, state wise and population wise, different regression formulae are required for estimation of stature and further research is encouraged and suggested to do according to state wise and over the different ethnic groups. This study has been performed in a small sample which may not be representative of the population and that is a limitation of this study.

\section{ACKNOWLEDGEMENT}

We are thankful to the Department of Anatomy of MB Kedia Dental college, Birgunj for helping us in carrying out this research and we are also thankful to the participants without whom this study would not have been possible and special thanks to Ravi Kumar Bhaskar for statistical analysis. 


\section{REFERENCES}

1. Agnihotri AK, Kachhwaha S, Joaheer V, Singh AP. Estimating stature from percutaneous length of tibia and ulna in Indo-Mauritian population. Forensic Sci Int. 2009 May 30;187(1-3):109.

2. Kaore DA, Kamdi DA, Kaore DS. Stature Estimation From Tibial Length. Natl J Integrated Res Med. 2012 Jan 26;3(2):51-6.

3. Pan N. Lengths of long bones and their proportions to body height in Hindus. J Anat. 1924;58:374-8.

4. Siddiqui $H$, Shah MA. Estimation of stature from long bones of Punjabis. Indian J Med Res. 1944;31:105-8.

5. Athawale NC. Anthropological study of height from length of forearm bones. A study of one hundred Maharashtrian male adults of ages between twenty five and thirty years. Am J Phys Anthropol. 1963;21:105-12.

6. Patel MP, Joshi NB, Dongre AN. Regression equation of height on tibial length. Indian J Med Res. 1964;52:531-4.

7. Anand N, Nath S. Estimation of stature through percutaneous measures of the upper and lower extremities among Rajputs of Pauri Garhwal. Indian J Forensic Sci. 1990;5:83-9.

8. Choi BY, Chae YM, Chung IH, Kang HS. Correlation between the postmortem stature and dried limbbone lengths of Korean adult males. Yonsei Med J. 1997;38:79-85.
9. Mohanty NK. Prediction of height from percutaneous tibial length amongst Oriya population. Forensic Sci Int. 1998;98:137-41.

10. De Mendonça MC. Estimation of height from the length of long bones in a Portuguese adult population. Am J Phys Anthropol. 2000;112:39-48.

11. Lal CS, Lala JK. Estimation of stature from tibial and ulnar lengths in North Bihar. J Indian Med Assoc. 1972;58:120-1.

12. Trotter $M$, Glesser GC. Estimation of stature from the long bones of American whites and negroes. Am J Phys Anthropol. 1952;(10):463-514.

13. Steele MF, Chenier TC. Arm-span, height, and age in black and white women. Ann Hum Biol. 1990;17(6):533-41.

14. Celbis $\mathrm{O}$, Agritmis $\mathrm{H}$. Estimation of the stature and the determination of sex from the radial and the ulnar bone lengths in a Turkish corpse sample. Forensic Sci Int. 2006 May 10;158(2-3):135-9.

15. Bhavna, Nath S. Use of lower limb measurements in reconstructing stature among Shia Muslims. Internet J Biolog Anthropol. 2008;22:18-24.

16. Ozaslan A, Iscan MY, Ozaslan I, Tugcu H, Koc S. Estimation of stature from body parts. Forensic Sci Int. 2003:132(1): 40-5.

17. Nagesh KR, Kumar GP. Estimation of stature from vertebral column length in South Indians. Leg Med. 2006;8(5):269-72. 